\title{
Complex visual hallucinations and delusional infestation comorbidity
}

\author{
Alucinações visuais complexas e delírios de infestação
}

Fábio Lopes Rocha', Paulo Caramelli², Laura C. Oliveira ${ }^{3}$

${ }^{1}$ Clínica Psiquiátrica/Pós-Graduação em Ciências da Saúde; Instituto de Previdência dos Servidores do Estado de Minas Gerais (IPSEMG), Belo Horizonte MG, Brazil; ${ }^{2}$ Departamento de Clínica Médica; Faculdade de Medicina da Universidade Federal de Minas Gerais (UFMG), Belo Horizonte MG, Brazil; ${ }^{3}$ Clínica Psiquiátrica; Instituto de Previdência dos Servidores do Estado de Minas Gerais (IPSEMG), Belo Horizonte MG, Brazil. Correspondence: Fábio Lopes Rocha; Rua do Otoni 106; 30150-270 Belo Horizonte MG - Brasil; E-mail: rochafl@uol.com.br Conflict of interest: Fábio Lopes Rocha is/was the main investigator in clinical trials (current: AstraZeneca, Eli Lilly, Roche, and Servier; past: Janssen Cilag, Pfizer). For the remaining authors, none were declared.

Received 06 February 2012; Accepted 13 February 2012

Complex visual hallucinations (CVH) may emerge in several circumstances, generally detailed and colorful, during clear sensorium. They include people or children, Lilliputian images, deformed faces, animals and complex scenes, being more common during poor light or personal isolation, with variable insight. Treatment of $\mathrm{CVH}$ depends on the etiology, albeit evidence for pharmacotherapy is limited ${ }^{1}$.

Delusional infestation (DI) is an uncommon condition, in which patients believe that insects or small vermin are living or thriving on and in the skin or body. It may be the sole psychiatric disturbance or in association with an underlying disorder. Presence of hallucinations congruent with the delusions does not exclude the diagnosis ${ }^{2}$. DI treatment is particularly based on second generation antipsychotics (SGA) ${ }^{3}$. We report a case presenting DI and CVH treated with aripiprazole.

\section{CASE REPORT}

A 95-year-old woman, with four years of schooling, had a seven-year history of DI. In the beginning, there were itching and prickling sensations on arms and head. Subsequently, she felt small worms, with different shapes and colors, crawling through her skin or swirling around her body. After two years, she began to see small pumpkins and flowers coming out of her body and lettuce crawling on the table. She complained of water trickling out of walls and forming puddles on the ground. Occasionally, she saw small children walking on the walls and also worms on the floor and walls. Sometimes, the parasites set fire to small objects. She became upset with her family and physicians who did not believe her.

Throughout this period, the patient did not show depressive or cognitive symptoms. She had no previous psychiatric history. She presented age-related macular degeneration for eight years and hypoacusia for four years. Previous treatment consisted of quetiapine, risperidone, olanzapine and pericyazine, without improvement. She scored 26/30 in the MiniMental State Examination (MMSE). The clock drawing test showed some perseveration and some visuospatial errors. There were no focal neurological signs. She refused to perform magnetic resonance.

Two diagnoses were given: CVH associated with visual impairment due to macular degeneration and DI. The clock test suggested cognitive impairment, but without clinical significance. Aripiprazole, $15 \mathrm{mg}$ daily, was prescribed. Within one week, CVH almost disappeared. One month later, sometimes, she still saw lettuce on the table crawling out of the room. She stated that the parasites disappeared, but she knew they were in her house. Two months later, she was asymptomatic and remained so for one year, without side effects, except for mild Parkinsonism. Aripiprazole was withdrawn recently. The patient scored 20/30 in the MMSE, but examination was limited by worsening of the visual deficit and hypoacusia. Verbal fluency was impaired (six animals/ minute), and dementia diagnosis was considered.

\section{DISCUSSION}

CVH may affect healthy individuals and are also seen in several pathological states, such as Charles-Bonnet Syndrome (CBS). CBS is diagnosed when a person has CVH alongside deteriorating vision, with full insight and in the absence of another psychopathology. It occurs after visual pathway damage ${ }^{1}$. True CBS is rare, and most cases have CBS plus (presence of a neuropsychiatric disorder or absence of insight $)^{4}$. As the patient suffered from macular degeneration, CBS plus could be considered. It is possible that the comorbidity with DI contributed to the lack of insight. The patient refused to be submitted to neuroimaging. Hence, CNS lesions could not be excluded.

DI occurs more frequently in elderly subjects, predominantly females, as in our case. Symptoms' duration was seven years, longer than usually reported ${ }^{2}$. Duration of DI seems to be a prognostic factor, with shorter courses indicating better outcome $e^{2}$. Primary ideational disturbance and delusional 
interpretations related to abnormal sensations of dermatological, neurological or metabolic origin are mechanisms suspected to be involved in DI. Tactile or visual hallucinations are also suggested as source, trigger factor, or an extra feature of the thought disturbance.

Due to side effects of classical antipsychotics, SGA constitute alternatives for DI treatment ${ }^{3,5}$. In relation to $\mathrm{CVH} /$
CBS plus, evidence for SGA use is sparse, comprising only risperidone and olanzapine ${ }^{1}$. To the best of our knowledge, this is the first report of successful CVH/CBS plus treatment with aripiprazole, particularly the comorbidity of $\mathrm{CVH}$ plus with DI. The patient had good tolerability, with complete symptomatic relief. Further trials are warranted to study the true efficacy of SGA in this clinical context.

\section{References}

1. Mocellin R, Walterfang M, Velakoulis D. Neuropsychiatry of complex visual hallucinations. Aust N ZJ Psychiatry 2006;40:742-751.

2. Trabert W. 100 years of delusional parasitosis. Meta-analysis of 1,223 case reports. Psychopathol 1995;28:238-246.

3. Lepping P, Russell I, Freudenmann, RW. Antipsychotic treatment of primary delusional parasitosis: systematic review. $\mathrm{Br} J$ Psychiatry 2007:191:198-205.
4.

Howard R, Levy R. Charles Bonnet syndrome plus: complex visual hallucinations of Charles Bonnet syndrome type in late paraphrenia. Int J Geriatr Psychiatry 1994;9:399-404.

5. Rocha FL, Hara C. Aripiprazole in delusional parasitosis: Case report. Prog Neuropsychopharmacol Biol Psychiatry 2007;31:784-786. 